\title{
Roseobacter algicola sp. nov., a New Marine Bacterium Isolated from the Phycosphere of the Toxin-Producing Dinoflagellate Prorocentrum lima
}

\author{
B. LAFAY, ${ }^{1}$ R. RUIMY, ${ }^{1}$ C. RAUSCH DE TRAUBENBERG,${ }^{2}$ V. BREITTMAYER, ${ }^{3}$ \\ M. J. GAUTHIER, ${ }^{3}$ AND R. CHRISTEN ${ }^{1 *}$ \\ Centre National de la Recherche Scientifique and Université Paris VI, Station Zoologique, F-06230 \\ Villefranche-sur-Mer, ${ }^{1}$ IFREMER, Centre de Nantes, F-44037 Nantes Cedex 01, ${ }^{2}$ and \\ Institut National de la Santé et de la Recherche Médicale Unité 303, \\ F-06300 Nice ${ }^{3}$ France
}

\begin{abstract}
We describe a new species on the basis of phenotypic characteristics and the results of an analysis of small-subunit rRNA sequences. Three strains of this organism were isolated from a culture of the toxinproducing dinoflagellate Prorocentrum lima. These bacteria are gram-negative, strictly aerobic, ovoid organisms that are motile by means of one or two subpolar flagella. They grow at temperatures ranging from 10 to $37^{\circ} \mathrm{C}$ and in the presence of $\mathrm{NaCl}$ concentrations ranging from 0.1 to $2 \mathrm{M}$ and have an absolute requirement for sodium ions. They are strictly aerobic with a nonfermentative type of metabolism and are not able to grow anaerobically in presence or absence of nitrate. They do not denitrify. They exhibit oxidase, catalase, gelatinase, esculinase, $\beta$-galactosidase, and (to a lesser extent) amylase activities. The three strains which we examined require thiamine and biotin for growth. They grow only when glucose, trehalose, saccharose, fructose, maltose, pyruvate, malate, citrate, esculin, 2-ketoglutarate, 5-ketogluconate, glutamate, or shikimate is present as a sole carbon source. The three strains have identical small-subunit rRNA sequences. A phylogenetic analysis of these sequences revealed that these bacteria belong to the alpha subdivision of the Proteobacteria and that they form a distinct and robust monophyletic group with Roseobacter denitrificans and Roseobacter litoralis. This result and the general phenotypic characteristics of the organisms place them in the genus Roseobacter, although they do not produce bacteriochlorophyll $a$, in contrast to previously described Roseobacter species. On the basis of the phenotypic and genetic similarities of these strains, we assigned them to a single species, for which the name Roseobacter algicola is proposed. The type strain is $R$. algicola FF3 (= ATCC 51440).
\end{abstract}

The genus Roseobacter was created to comprise two bacterial species, Roseobacter denitrificans and Roseobacter litoralis, which have been isolated from the surfaces of green seaweeds but not from seawater; these aerobic, pink-pigmented bacteria contain bacteriochlorophyll $a(16,17)$. The genus Roseobacter differs phenotypically from the closely related genus Erythrobacter in carotenoid composition, bacteriochlorophyll-protein complex composition, and cell shape (16).

Three bacterial strains that were isolated recently from a culture of the toxin-producing dinoflagellate Prorocentrum lima have been shown to produce okadaic acid (14). In this paper we show that on the basis of the results of a phenotypic examination and phylogenetic analyses of small-subunit rRNA these bacteria should be included in the genus Roseobacter, although none of the strains produces bacteriochlorophyll $a$. All of the data suggest that these three strains belong to the same new species, for which we propose the name Roseobacter algicola; strain FF3 (= ATCC 51440) is the type strain of this species.

\section{MATERIALS AND METHODS}

Bacterial strains and growth conditions. Roseobacter algicola $\mathrm{ML} 4, \mathrm{FF} 2$, and $\mathrm{FF}^{\mathrm{T}}$ ( $\mathrm{T}=$ type strain) (14) were isolated from a stationary culture of the toxin-producing marine dinoflagellate Prorocentrum lima PL2V (Instituto Espanol de Oceanographia, Vigo, Spain). Strain ML4 was isolated from the culture medium on marine agar 2216 (MA) (Difco Labo-

\footnotetext{
* Corresponding author.
}

ratories, Detroit, Mich.) (23), whereas strains FF2 and FF3 ${ }^{\mathrm{T}}$ were isolated from algal cells on a solid medium consisting of culture medium from which algae had been removed by filtration with membrane filters (pore size, $0.2 \mu \mathrm{m}$; Millipore Corp., Bedford, Mass.) supplemented with $15 \%$ (wt/vol) agar. Production of okadaic acid was demonstrated after one subculture on MA for strains ML4 and FF2 and after two subcultures for strain FF3 ${ }^{\mathrm{T}}$ (14). Reference marine organism Roseobacter litoralis ATCC 49566, which was included in the small-subunit rRNA analyses described below, was kindly provided by $T$. Shiba. All strains were maintained in marine broth 2216 (MB) (Difco) at $-80^{\circ} \mathrm{C}$ before tests were performed. Bench cultures were prepared either with artificial Shioi's marine medium, as adapted by Shiba (17) (SMM), or MA and were incubated at room temperature $\left(23\right.$ to $\left.25^{\circ} \mathrm{C}\right)$ unless indicated otherwise. None of the strains grew on thiosulfate-citrate-bile salts agar.

Electron microscopy. Detailed cell shapes and flagellar characteristics were determined by transmission electron microscopy. Cells were negatively stained with $1 \%$ (wt/vol) phosphotungstic acid in distilled water ( $\mathrm{pH} 6.5)$ as described by Jahn (10) and were observed with a Philips model CM2 transmission electron microscope at $100 \mathrm{kV}$ (Centre Commun de Microscopie Appliquée, Faculté des Sciences, Nice, France).

Phenotypic analysis. Routine tests (Gram staining tests and oxidase, catalase, $\beta$-galactosidase, gelatinase, alkaline phosphatase, tributyrase, phospholipase, esculinase, tweenase 20 , tweenase 80 , lecithinase, DNase, amylase, alginase, agarase, and urease activity tests) were performed with exponential cells as described by Smibert and Krieg (18). Pigment production (including color of colonies and diffusible pigment production) and luminescence were determined on MA, MA sup- 
plemented with $0.5 \%$ (wt/vol) starch, SMM, and King's B medium after 1 week. Reduction of nitrate and reduction of nitrite were determined after 6 days of incubation in SMM containing $0.2 \% \mathrm{KNO}_{3}$ at $\mathrm{pH}$ 7.6. Metabolism of carbohydrates was determined by the oxidation-fermentation method of Leifson (12), using maltose as the sole source of carbon and energy. Anaerobic growth was studied by using MB supplemented or not supplemented with $0.2 \% \mathrm{KNO}_{3}$ and a BBL GasPak system (Becton Dickinson and Co., Cockeysville, Md.). Arginine dihydrolase, lysine decarboxylase, and ornithine decarboxylase activities were determined by using techniques described by Bauman et al. $(2,3)$ for marine bacteria. We determined the effects of $\mathrm{pH}(\mathrm{pH} 5,6,7,8,9$, and 10), temperature $\left(4,20,37\right.$, and $\left.44^{\circ} \mathrm{C}\right)$, and $\mathrm{NaCl}$ concentration $(0$, $0.01,0.1,0.25,0.5,1,1.5$, and $2 \mathrm{M}$ ) on growth in MB. Results were recorded after 3 days of incubation. Whether $\mathrm{Na}^{+}$ions were required was determined by the method of Colwell and Wiebe (6)

We determined whether carbon sources were utilized by using the organic acid medium used by Shiba (16) and the following substrates, each at a concentration of $0.1 \%(\mathrm{wt} / \mathrm{vol})$ : DL-arabinose, ribose, DL-xylose, galactose, D-glucose, D-fructose, D-mannose, rhamnose, cellobiose, maltose, lactose, Dmelibiose, saccharose, trehalose, raffinose, gentiobiose, melezitose, D-turanose, D-lyxose, D-fucose, glycerol, erythritol, dulcitol, adonitol, inositol, D-mannitol, D-sorbitol, xylitol, methanol, amygdalin, inulin, esculin, salicin, $N$-acetyl-glucosamine, D-gluconate, acetate, pyruvate, succinate, malate, citrate, 2-ketogluconate, 5 -ketogluconate, 2 -ketoglutarate, butyrate, DL- $\beta$-hydroxybutyrate, L-glutamate, shikimate, L-proline, L-histidine, L-arginine, L-lysine, and L-tryptophan. Whether polyhydroxybutyrate was accumulated was determined by the method of Baumann and Baumann (2). Requirements for thiamine, biotin, nicotinic acid, and sodium panthotenate were determined by the method used by Shiba for Roseobacter litoralis and Roseobacter denitrificans (16).

Susceptibilities to inhibitors were determined on MA by using the standard antibiogram method (5) and the following antibiotics (Bio-disks; B-D Mérieux, Marcy l'Etoile, France): chloramphenicol $(30 \mu \mathrm{g})$, erythromycin $(15 \mu \mathrm{g})$, streptomycin $(10 \mu \mathrm{g})$, kanamycin $(10 \mu \mathrm{g})$, streptomycin $(10 \mu \mathrm{g})$, novobiocin $(30 \mu \mathrm{g})$, penicillin $\mathrm{G}(10 \mathrm{U})$, cephaloridine $(30 \mu \mathrm{g})$, tetracycline $(30 \mu \mathrm{g})$, neomycin $(30 \mu \mathrm{g})$, and the vibriostatic agent pteridin 0/129 $(100 \mu \mathrm{g})$.

Production of bacteriochlorophyll $a$ was determined by both spectrometric analysis and thin-layer chromatography of methanolic cell extracts. Cells grown in $200 \mathrm{ml}$ of SMM with no light at all were collected by centrifugation at $5000 \times g$, and $20^{\circ} \mathrm{C}$ for $5 \mathrm{~min}$ at the mid-exponential phase, and the resulting pellet was extracted in the dark at $4^{\circ} \mathrm{C}$ with $100 \mathrm{ml}$ of methyl alcohol. The methanolic extract was concentrated under a vacuum (Rotavapor) at $35^{\circ} \mathrm{C}$ in the dark to a volume of approximately $1 \mathrm{ml}$. The presence of pigments was determined by visible spectrophotometry (350 to $900 \mathrm{~nm}$ ) with a Beckman model DU70 UV-visible spectrophotometer. The remaining extract was lyophilized, dissolved in $100 \mu \mathrm{l}$ of methyl alcohol-acetone (1:1), and loaded onto a silica gel thin-layer chromatography plate (Kiesel Gel 60; Merck, Darmstadt, Germany). The plate was developed with petroleum ether-acetone-benzene $(85: 40: 5)$.

DNA amplification. The method used to prepare bacterial DNA for PCR was adapted from the method of Sritharan and Barker (21). Bacteria were grown on marine agar, and colonies were suspended in $200 \mu \mathrm{l}$ of lysis mixture $(10 \mathrm{mM}$ Tris [pH 8.0], $1 \mathrm{mM}$ EDTA, 1\% Triton X-100) and boiled for $5 \mathrm{~min}$. After a single chloroform extraction, $5 \mu l$ of supernatant was used to amplify the small-subunit rRNA genes with two prim- ers, which corresponded to positions 8 to 28 and 1498 to 1509 in the Escherichia coli small-subunit rRNA sequence. The initial denaturation step consisted of heating the reaction mixture at $95^{\circ} \mathrm{C}$ for $180 \mathrm{~s}$, and this was followed by an annealing step $\left(52^{\circ} \mathrm{C}\right.$ for $\left.60 \mathrm{~s}\right)$ and an extension step $\left(72^{\circ} \mathrm{C}\right.$ for $\left.90 \mathrm{~s}\right)$. The thermal profile used subsequently was as follows: 25 cycles consisting of denaturation at $94^{\circ} \mathrm{C}$ for $30 \mathrm{~s}$, annealing at $52^{\circ} \mathrm{C}$ for $60 \mathrm{~s}$, and extension at $72^{\circ} \mathrm{C}$ for $90 \mathrm{~s}$. A final extension step was performed at $72^{\circ} \mathrm{C}$ for $5 \mathrm{~min}$. This amplification reaction produced 1.5-kb DNA molecules.

PCR product direct sequencing. The PCR products were analyzed on a $1 \%$ low-melting-point agarose gel that included a molecular weight standard for quantification of the PCR products. The PCR products were directly sequenced by using a protocol described by Anderson et al. (1), with slight modifications. We determined almost the entire small-subunit rRNA sequence (corresponding to positions 29 to 1425 in the $E$. coli rRNA sequence) for each new strain and for $R o$ seobacter litoralis. Eleven DNA primers were used in the sequencing reaction. These primers corresponded to the following positions in the $E$. coli sequence: primer S2, positions 99 to 119 ; primer S3, positions 242 to 262; primer S4, positions 342 to 356 ; primer $\mathrm{S} 6$, positions 518 to 534 ; primer $\mathrm{S} 8$, positions 684 to 702 ; primer S10, positions 906 to 925 ; primer S12, positions 1099 to 1114 ; primer S14, positions 1223 to 1240 ; primer S15, positions 1384 to 1400 ; and primer S17, positions 1493 to 1509 . A reverse primer (positions 8 to 28 ) was used in conjunction with primer S17 to amplify the small-subunit ribosomal DNAs.

Phylogenetic analysis and alignment: general procedure. The phylogenetic data described below were obtained (i) by using successive alignment and phylogeny procedures and (ii) by reinvestigating deep branching patterns after close relationships were determined. In each phylogenetic analysis, we restricted the comparisons to nucleotide positions that were aligned without doubt. Some analyses were performed several times, with or without small domains that could have reached the point of saturation for mutations. Although this approach was probably not as efficient as carefully weighting each position independently, it was easier and was probably a reasonable compromise considering the possible problems of crossing over that sometimes affect rRNA sequences (20). We also performed some analyses several times by including and excluding particular species that had high rates of mutation or that were distant outgroups, in order to better resolve relationships among closely related species (19). For each phylogenetic analysis, in order to keep computation times within reasonable limits, it was not possible to include all representatives of outgroups and ingroups in maximum-parsimony and maximum-likelihood analyses. This problem was alleviated by performing multiple analyses with different outgroups and different ingroups (as determined by the neighbor-joining analysis). All sequence alignments and species selection were done by using computer programs developed by us and available on request from $\mathrm{R}$. Christen.

Phylogenetic methods. (i) Neighbor joining. A neighborjoining algorithm like that developed by Saitou and Nei (15) was used. The program was rewritten to include inputs and outputs compatible with the ribosomal database and other programs developed in our laboratory (running on 386-compatible personal computers and above).

(ii) Maximum parsimony. The PAUP program (22) for MacIntosh computers was used for the maximum-parsimony analysis. All topologies were first obtained by using the heuristic option. According to the time used, a branch and bound search was then undertaken by using the full data set or a 
restricted set of species selected on the basis of the results of the heuristic search. When several most-parsimonious trees were obtained, a $100 \%$ consensus tree was constructed and treated as the most parsimonious tree for constructing figures. Finally, a bootstrap analysis was performed (heuristic option) to check each topology for robustness. We favored a large number of analyses and 100 replications for each analysis rather than a high number $(1,000)$ of bootstrap replications, since our experience has shown that increasing the number of bootstrap replications to more than 100 usually has only a small influence on the results compared with the choice of species.

(iii) Maximum likelihood. The fDNAml program, which was derived from DNAML program (7) and was rewritten by G. J. Olsen (University of Illinois, Urbana), was used with a Hewlett-Packard model 700 workstation. All analyses were performed by using the global option (in fact, F Y G options). Finally, all trees were constructed by using a Macintosh computer and a program (njplot) developed by M. Gouy (URA 243, Centre National de la Recherche Scientifique, Université Claude Bernard, Villeurbanne, France), which allowed a formal tree representation (Newick's format) to be transformed into MacDraw drawings. Only topologies that were found to be similar by all three methods were retained as "true trees." Recent theoretical works have indeed demonstrated that convergence of the results of all three methods is a very strong indication that the correct phylogeny has been determined ( 9 , $11)$.

rRNA sequences from the following species were used to construct a rooted phylogenetic tree (see Fig. 3): Afipia clevelandensis, Caulobacter bacteroides, Azospirillum lipoferum, Porphyrobacter neustonensis, Sphingomonas adhaesiva, Rhodopseudomonas marina, Bartonella bacilliformis, Rhizobium leguminosarum, Roseobacter denitrificans, Paracoccus denitrificans, Hirschia baltica, Ehrlichia ewingii, Wolbachia pipientis, and Rickettsia rickettsii. In addition, rRNA sequences from the following organisms were used to construct an unrooted tree (see Fig. 4): Rhodobacter capsulatus, Rhodobacter sphaeroides, the Sargasso Sea bacterium (4), Hyphomonas jannaschiana, and Hyphomonas sp.

Bacterial strain accession numbers. Strains ML4, FF2, and $\mathrm{FF}^{\mathrm{T}}$ have been deposited in the American Type Culture Collection as strains ATCC 51441, ATCC 51442, and ATCC $51440^{\mathrm{T}}$, respectively.

Nucleotide sequence accession numbers. The small-subunit rRNA nucleotide sequences determined in this study have been deposited in the EMBL database under accession numbers X78313 (strain ML4), X78314 (strain FF2), X78315 (strain $\mathrm{FF}^{\mathrm{T}}$ ), and X78312 (Roseobacter litoralis ATCC 49566). The accession numbers for the other nucleotide sequences used to construct phylogenetic trees are as follows: Afipia clevelandensis, M69186; Caulobacter bacteroides, M83796; Azospirillum lipoferum, M59061; Porphyrobacter neustonensis, M96745; Sphingomonas adhaesiva, X72720; Rhodopseudomonas marina, M27534; Bartonella bacilliformis, M65249; Rhizobium leguminosarum, X67227; Roseobacter denitrificans, M96746; Paracoccus denitrificans, X69159; Hirschia baltica, X52909; Ehrlichia ewingii, M82801; Wolbachia pipientis, X61768; Rickettsia rickettsii, M21293; Rhodobacter capsulatus, M34129; Rhodobacter sphaeroides, X53853; Sargasso Sea bacterium (4), M63810; Hyphomonas jannaschiana, M83806; and Hyphomonas sp., M83812.

\section{RESULTS}

Cell shape, Gram staining results, and motility. The three strains of Roseobacter algicola were gram-negative, non-spore- forming organisms. Cells actively growing in MB and Shiba's medium at $22^{\circ} \mathrm{C}$ were ovoid rods that were 2 to $3 \mu \mathrm{m}$ long and 0.8 to $1.5 \mu \mathrm{m}$ in diameter, were motile by means of one or two subpolar flagella, and contained several refringent spherical granules (Fig. 1).

Culture and growth characteristics. On MA and SMM incubated at 23 to $25^{\circ} \mathrm{C}$, young colonies were circular (diameters, 0.5 to $1 \mathrm{~mm}$ ), smooth, convex, and white with regular edges. After 6 days of incubation, colonies were $2 \mathrm{~mm}$ in diameter and pinkish beige with brownish edges (strain ML4), and no diffusible or fluorescent pigments were produced. No bioluminescence was detected. Strain ML4 produced a faint brown diffusible pigment in King B medium. In MB and SMM broth, all of the strains exhibited slow growth in the top 1 centimeter only, and no superficial pellicle was formed. Growth was strongly enhanced by vigorous aeration. All three strains grew at temperatures between 10 and $37^{\circ} \mathrm{C}$, and optimal growth occurred at 25 to $30^{\circ} \mathrm{C}$. The organisms tolerated a range of $\mathrm{pH}$ values ( $\mathrm{pH} 6$ to 9; optimal growth occurred at $\mathrm{pH} 7.5$ ) and $\mathrm{NaCl}$ concentrations $(0.1$ to $2 \mathrm{M})$. They had an absolute requirement for $\mathrm{Na}^{+}$cations, since no growth was observed in a medium without $\mathrm{Na}^{+}$, even when osmolarity was increased by adding dextran (which was not metabolized).

Physiological and biochemical characteristics. The phenotypic characteristics that differentiated Roseobacter algicola from Roseobacter litoralis and Roseobacter denitrificans are shown in Table 1. Roseobacter algicola strains exhibited oxidase, catalase, gelatinase, esculinase, and $\beta$-galactosidase activities and a faint amylolytic activity. Tweenase, lecithinase, tributyrase, phospholipase, alkaline phosphatase, alginase, agarase, DNase, arginine dihydrolase, lysine decarboxylase, and ornithine decarboxylase activities were not detected. A urease activity was detected only in strain FF2 (Table 2). Strains ML4 $\mathrm{FF} 2$, and $\mathrm{FF}^{\mathrm{T}}$ were not able to reduce nitrate or to grow anaerobically with or without nitrate. They exhibited oxidative metabolism of glucose. All three strains were able to use the following substrates as sole sources of carbon and energy: glucose, trehalose, saccharose, fructose, maltose, pyruvate, malate, citrate, esculin, 2-ketoglutarate, 5-ketogluconate, glutamate, and shikimate. Some other organic compounds were used variably (Table 2). None of the strains accumulated polyhydroxybutyrate intracellularly. Bacteriochlorophyll $a$ was not detected in methanolic extracts of strains ML4, FF2, and FF3 ${ }^{\mathrm{T}}$ (Fig. 2). The peak observed at $413 \mathrm{~nm}$ might correspond to Mg-porphyrin compounds. Considering the strict conditions used during the extraction process (dark, low temperature), it can reasonably be assumed that these bacteria do not produce bacteriochlorophyll $a$.

Susceptibility to inhibitors. All three strains were susceptible to chloramphenicol, erythromycin, novobiocin, and penicillin $G$ and exhibited slight susceptibility to kanamycin and tetracycline. They were resistant to the other antibiotics tested and to the vibriostatic agent pteridin 0/129. However, the results obtained for pteridin $0 / 129$ were not completely reliable since the test had to be performed in a saline medium (13).

Small-subunit rRNA sequence and phylogenetic analyses. The small-subunit rRNA sequences of isolates FF2, $\mathrm{FF}^{\mathrm{T}}$, and ML4 were identical. Because of this, all phylogenetic analyses were performed with one of these small-subunit rRNA sequences. All sequences were aligned by comparing them with a database containing more than 2,000 aligned eubacterial small-subunit rRNA sequences. Phylogenetic analyses that included representatives of all eubacterial phyla and all proteobacterial subdivisions revealed that the three new bacteria belong to the alpha subdivision of the Proteobacteria (data not 

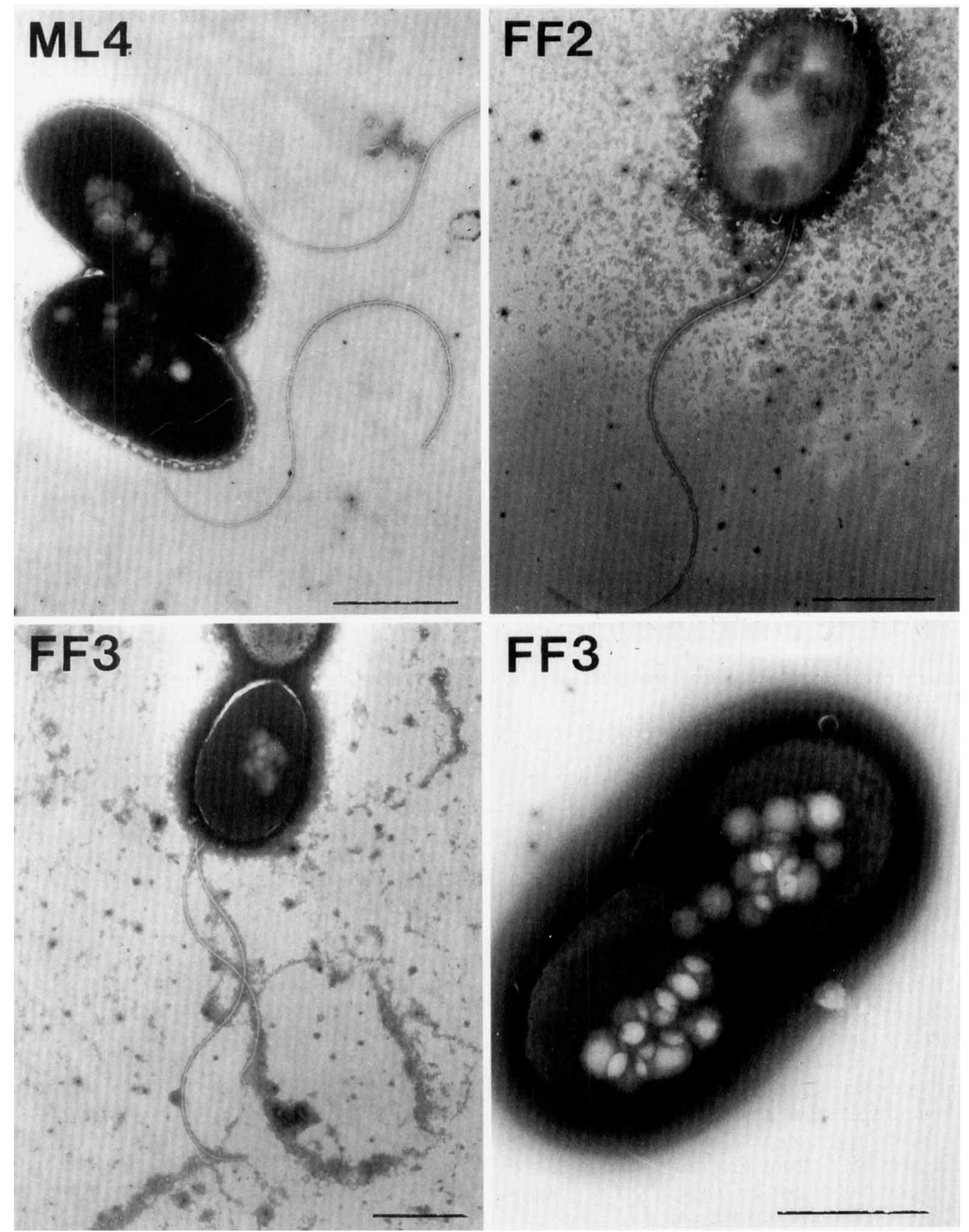

FIG. 1. Electron micrographs of negatively stained strain ML4, FF2, and FF ${ }^{\mathrm{T}}$ cells grown on SMM. The cells were stained at the end of the exponential phase of growth. Bars $=1 \mu \mathrm{m}$

shown). The phylogenetic position of the new bacteria was then investigated in more detail by including other representatives of the alpha subdivision of the Proteobacteria and representatives of the four other subdivisions of the Proteobacteria (the beta, gamma, delta, and epsilon subdivisions) as outgroups. The analyses were performed by using the following three phylogenetic methods: the neighbor-joining method, the maximum-parsimony method, and the maximum-likelihood method. The results of all analyses were always consistent, regardless of which method was used or which representatives of the outgroups were used. The results of these analyses are summarized in Fig. 3. In all analyses, the new bacteria clustered with members of the alpha subdivision along with mem- bers of the genus Roseobacter. We also investigated the phylogenetic position of the new bacteria by using a smaller set of sequences from taxa related to the genus Roseobacter and the three methods described above. A maximum-parsimony analysis was performed by using the exhaustive search option, and with this method we constructed one most-parsimonious tree (length, 402; consistency index, 0.668; retention index, 0.706). All of the branches were well supported by the results of a maximum-likelihood analysis (all branches exhibited a significantly positive length at $P<0.01$ ) and by the results of 100 bootstrap replications in the maximum-parsimony analysis. We obtained the same topology with all three methods, showing not only that the new bacteria are closely related to Ro- 
TABLE 1. Phenotypic characteristics that differentiate Roseobacter algicola from previously described Roseobacter species

\begin{tabular}{|c|c|c|c|}
\hline Characteristic & Roseobacter litoralis ${ }^{a}$ & Roseobacter denitrificans ${ }^{a}$ & Roseobacter algicola \\
\hline Morphology & Rods or ovoid rods & Rods or ovoid rods & Ovoid rods \\
\hline No. and arrangement of flagella & 1-3, subpolar & $1-3$, subpolar & 1-2, subpolar \\
\hline Growth at $4^{\circ} \mathrm{C}$ & $+1-^{b}$ & + & - \\
\hline Growth at $37^{\circ} \mathrm{C}$ & - & - & + \\
\hline Growth anaerobically in the presence of $\mathrm{NO}_{3}$ & - & $+^{c}$ & - \\
\hline Nitrate reduced to nitrite & - & + & - \\
\hline \multicolumn{4}{|l|}{ Hydrolysis of: } \\
\hline Tween 80 & + & + & - \\
\hline Starch & - & - & $(+)$ \\
\hline \multicolumn{4}{|l|}{$\begin{array}{l}\text { Utilization of the following compounds as } \\
\text { sole sources of carbon: }\end{array}$} \\
\hline Maltose & - & - & + \\
\hline Saccharose & - & - & + \\
\hline Trehalose & - & - & + \\
\hline Esculin & - & - & + \\
\hline Shikimate & - & - & + \\
\hline Proline & + & + & V \\
\hline 2-Ketoglutarate & + & - & + \\
\hline$\beta$-Hydroxybutyrate & + & + & - \\
\hline Requirement for nicotinic acid & + & + & - \\
\hline Production of bacteriochlorophyll $a$ & + & + & - \\
\hline Nondiffusible pigment & Pink to red & Pink to red & Beige \\
\hline Diffusible pigment & - & - & None or brown \\
\hline $\mathrm{G}+\mathrm{C}$ content of DNA ( $\mathrm{mol} \%)$ & $56.3-58.1$ & 59.6 & ND \\
\hline
\end{tabular}

${ }^{a}$ Data from references 16 and 17 .

$b+$, positive reaction; - , negative reaction; $(+)$, weakly positive reaction; $V$, variable reaction (Table 2); ND, not determined.

${ }^{c}$ Under phototrophic conditions.

seobacter denitrificans and Roseobacter litoralis, but also that they form a robust monophyletic unit with these species (Fig. 4).

\section{DISCUSSION}

Species assignment. The ecological and phenotypic characteristics of strains $\mathrm{ML} 4, \mathrm{FF} 2$, and $\mathrm{FF}^{\mathrm{T}}$ suggested that these organisms are related to species belonging to the genus $R o-$ seobacter. The members of both groups were isolated from the surfaces (or vicinities) of algae, although Roseobacter litoralis and Roseobacter denitrificans are macroscopic seaweed inhabitants. Furthermore, ML4, FF2, and FF3 ${ }^{\mathrm{T}}$ exhibited a high level of phenotypic similarity to Roseobacter species since more than $90 \%$ of the phenotypic traits analyzed in our study were identical in both groups (phenotypic traits that differentiate strains ML4, FF2, and $\mathrm{FF}^{\mathrm{T}}$ from Roseobacter litoralis and Roseobacter denitrificans are shown in Table 2). The phenotypic characteristics of strains ML4, FF2, and FF3 ${ }^{\mathrm{T}}$ are suffciently similar to assign these organisms to a single species.

TABLE 2. Biochemical and physiological characteristics which differentiate Roseobacter algicola strains

\begin{tabular}{lccc}
\hline Characteristic & Strain ML4 & Strain FF2 & Strain FF3 \\
\hline Assimilation of: & & & \\
Acetate & - & + & + \\
Ribose & + & - & - \\
Melezitose & - & - & + \\
Mannitol & - & + & - \\
Turanose & - & + & - \\
Proline & - & + & + \\
Arginine & - & + & - \\
Urease activity & - & - & + \\
Brown pigment & \\
\hline
\end{tabular}

${ }^{a}$ On solid media (marine agar, SMM) supplemented with starch.
This conclusion was confirmed by the observation that all three of these strains have identical small-subunit rRNA sequences. However, our data are not conclusive enough to justify placing these organisms in the same species (8), and definitive assignment will require a determination of levels of DNA-DNA hybridization.

The results of our analyses of small-subunit rRNA sequences confirmed that Roseobacter litoralis and Roseobacter denitrificans form a well-defined taxon that deserves the rank of genus. The same analyses revealed an unambiguous affiliation between the new bacteria and the alpha subdivision of the Proteobacteria and the existence of a very robust monophyletic unit formed by the two previously described Roseobacter species and the three new strains (the results of all phylogenetic analyses were consistent and were strongly supported by bootstrap replication data). The new marine bacteria have some distinctive phenotypic characteristics that distinguish them

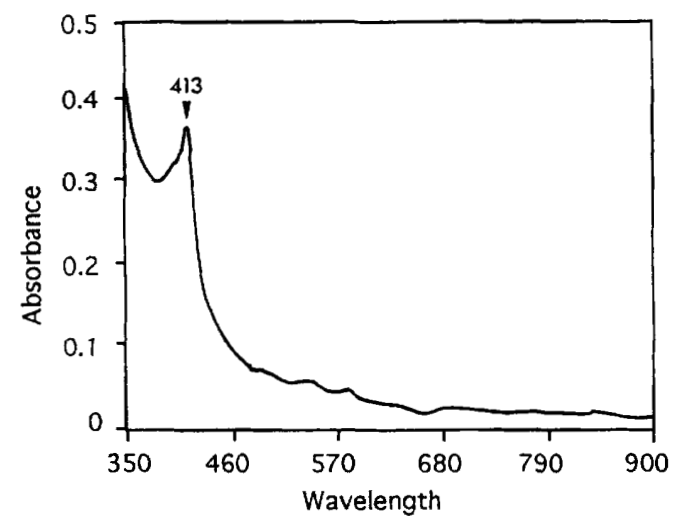

FIG. 2. Absorption spectrum of a methanolic extract of strain $\mathrm{FF}^{\mathrm{T}}$. 


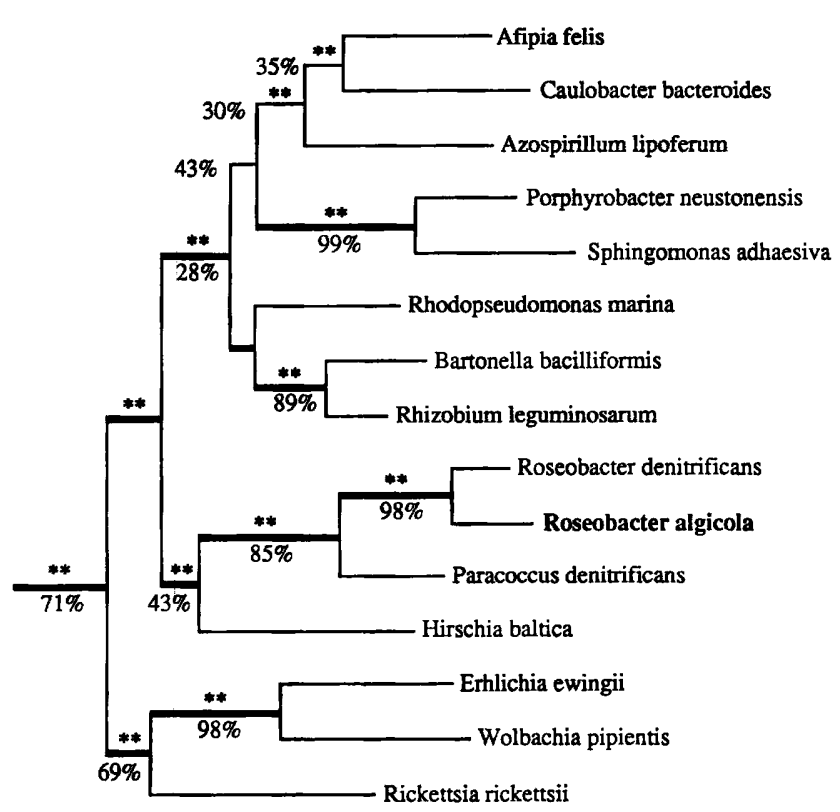

FIG. 3. Phylogenetic position of Roseobacter algicola sp. nov. within the alpha subdivision of the phylum Proteobacteria: rooted tree summarizing the results of phylogenetic analyses obtained by using three different methods based on comparisons of the small-subunit rRNA sequences of the new species and representative bacteria belonging to the phylum Proteobactena. The tree shown is part of a tree obtained by using a maximum-likelihood method and representatives of the other proteobacterial subdivisions as outgroups; branches significantly positive at $P<0.01$ are indicated by two asterisks. The thick lines indicate taxa that were also found in a neighbor-joining analysis of the same sequences. The same topology was obtained by using a maximum-parsimony method; one most-parsimonious tree was constructed by using the heuristic search option (length, 2,982; consistency index, 0.326 ; retention index, 0.521 ). Percentages that correspond to the values obtained from a bootstrap analysis when the maximumparsimony method was used are indicated under or next to the branches.

(Table 2); unlike Roseobacter litoralis and Roseobacter denitrificans, strains ML4, FF2, and $\mathrm{FF}^{\mathrm{T}}$ are thermotolerant, have a very restricted nutritional profile, and, more importantly, lack phototrophic activity since they do not produce bacteriochlo-

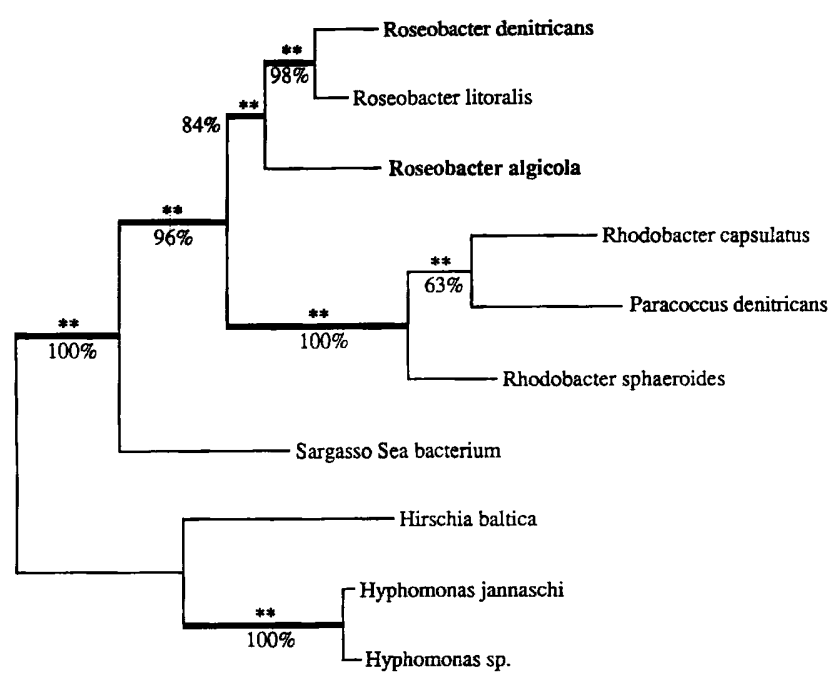

FIG. 4. Phylogenetic position of Roseobacter algicola sp. nov. within the genus Roseobacter: unrooted tree summarizing the results of phylogenetic analyses obtained by using three different methods to analyze small-subunit rRNA sequences of Roseobacter algicola and related species. For additional details see the legend to Fig. 3. rophyll $a$. The large numbers of differences observed between the small-subunit rRNA sequences of the new strains and those of the previously described Roseobacter species ( 74 differences with Roseobacter litoralis and 87 differences with $R o-$ seobacter denitrificans in 1,265 nucleotides) and the phenotypic differences provide strong evidence that a new species should be recognized. Although we still lack carotenoid, genomic, and fatty acid composition data to confirm that this bacterium has some of the important characteristics of the genus Roseobacter, considering the robusteness of the monophyletic taxon that includes these three species, we feel that it is more appropriate to assign this bacterium to the genus Roseobacter than to create a new genus. Consequently, we propose the name Roseobacter algicola (al.gi' co.la L. n. alga, alga; L. subst. cola, dweller; M. L. n. algicola, alga dweller).

Description of the type strain of Roseobacter algicola. The cells of the type strain of Roseobacter algicola (strain FF3) are ovoid (length, 2 to $3 \mu \mathrm{m}$; width, 0.8 to $1.6 \mu \mathrm{m}$ ) in the logarithmic growth phase. The cells are gram negative, do not form spores, and are motile by means of one or two subpolar flagella. Colonies on salt-containing agar media are beige when the cultures are young and pinkish beige after $96 \mathrm{~h}$ of incubation.

Cells grow at temperatures ranging from 10 to $37^{\circ} \mathrm{C}$, and optimal growth occurs at 25 to $30^{\circ} \mathrm{C}$. The cells have an absolute requirement for sodium ions and can grow in the presence of $\mathrm{NaCl}$ concentrations ranging from 0.1 to $2 \mathrm{M}$. The cells are strictly aerobic with a nonfermentative type of metabolism; they do not grow anaerobically on glucose in the presence or absence of nitrate. The cells are not able to denitrify. They exhibit oxidase, catalase, gelatinase, esculinase, $\beta$-galactosidase, and (to a lesser extent) amylase activities. They do not accumulate polyhydroxybutyrate. They use D-glucose, trehalose, saccharose, D-fructose, maltose, melezitose, acetate, pyruvate, malate, citrate, esculin, 2-ketoglutarate, 5-ketogluconate, L-proline, L-arginine, L-glutamate, and shikimate, but not DLarabinose, ribose, DL-xylose, galactose, D-mannose, rhamnose, cellobiose, lactose, D-melibiose, raffinose, gentiobiose, D-turanose, D-lyxose, D-fucose, glycerol, erythritol, dulcitol, adonitol, inositol, D-mannitol, D-sorbitol, xylitol, methanol, amygdalin, inulin, salicin, $N$-acetylglucosamine, D-gluconate, 2-ketogluconate, 2ketoglutarate, butyrate, DL- $\beta$-hydroxybutyrate, L-histidine, Llysine, and L-tryptophan. They do not produce bacteriochlorophyll $a . \mathrm{FF}^{\mathrm{T}}$ cells are resistant to oleandomycin, gentamicin, streptomycin, and neomycin, slightly susceptible to kanamycin and tetracycline, and susceptible to chloramphenicol, erythromycin, novobiocin, and penicillin $\mathrm{G}$.

On the basis of its small-subunit rRNA sequence, this bacterium belongs to the alpha subdivision of the Proteobacteria and is part of a distinct monophyletic group containing Roseobacter denitrificans and Roseobacter litoralis. Strain $\mathrm{FF}^{\mathrm{T}}$ was isolated from a culture of the toxin-producing dinoflagellate Prorocentrum lima PLV2 obtained from Vigo, Spain; this strain has been deposited in the American Type Culture Collection as strain ATCC $51440^{\mathrm{T}}$.

\section{ACKNOWLEDGMENTS}

We thank D. LeRudulier for performing spectrometric analyses of cell extracts and $T$. Shiba for bacterial strains.

This work was supported in part by funds from the Programme National "Phycotoxines marines" (IFREMER) and by a grant from IFREMER to $\mathrm{R}$. Christen.

\section{REFERENCES}

1. Anderson, R. D., C.-Y. Bao, D. T. Minnick, M. Veigl, and W. D. Sedwick. 1992. Optimization of double-stranded DNA sequencing for polymerase chain reaction products. USB Editorials Comments 19:39-40 and 57-58. 
2. Baumann, P., and L. Baumann. 1981. The marine Gram-negative eubacteria; genera Photobacterium, Beneckea, Alteromonas, Pseudomonas, and Alcaligenes, p. 1302-1330. In M. P. Starr, H. Stolp, H. G. Trüper, A. Balows, and H. G. Schlegel (ed.), The prokaryotes. Springer-Verlag, Berlin.

3. Baumann, P., L. Baumann, and M. Mandel. 1971. Taxonomy of marine bacteria: the genus Beneckea. J. Bacteriol. 107:268-294.

4. Britschgi, T. B., and S. J. Giovannoni. 1991. Phylogenetic analysis of natural marine bacterioplankton population by rRNA gene cloning and sequencing. Appl. Environ. Microbiol. 57:1707-1713.

5. Chabbert, Y. A. 1963. L'antibiogramme. Collection Techniques de Base Editions La Tourelle, St. Mandé, France.

6. Colwell, R. R., and W. J. Wiebe. 1970 . Core characteristics for use in classifying aerobic, heterotrophic bacteria by numerical taxonomy. Antonie Leeuwenhoek 29:344-358.

7. Felsenstein, J. 1990. PHYLIP package, version 3.3. Department of Genetics, University of Washington, Seattle.

8. Fox, G. E., J. D. Wisotzkey, and P. Jurtshuk. 1992. How close is close: 16S rRNA sequence identity may not be sufficient to guarantee species identity. Int. J. Syst. Bacteriol. 42:166-170.

9. Huelsenbeck, J. P., and D. M. Hillis. 1993. Success of phylogenetic methods in the four-taxon case. Syst. Biol. 42:247-264.

10. Jahn, K. 1986. Isolation and characterization of fimbriae from Escherichia coli, p. 381-388. In M. Sussman (ed.), The virulence of Escherichia coli. Reviews and methods. Academic Press, London.

11. Kim, J. 1993. Improving the accuracy of phylogenetic estimation by combining different methods. Syst. Biol. 42:331-340.

12. Leifson, E. 1963. Determination of carbohydrate metabolism of marine bacteria. J. Bacteriol. 85:1183-1184.

13. Merkel, J. R. 1972. Influence of salts on the vibriostatic action of 2,4diamino-6,7-diiosopropyl pteridine. Arch. Microbiol. 81:379-382.
14. Rausch de Traubenberg, C. 1993. Interaction entre un dinoflagellé et sa microflore bactérienne associée: rôle des bactéries dans la toxicité de Prorocentrum lima Ehrenberg (Dodge). Ph.D. thesis. Université de Nantes, Nantes, France.

15. Saitou, N., and M. Nei. 1987. The neighbor-joining method: a new method for reconstructing phylogenetic trees. Mol. Biol. Evol. 4:406-425.

16. Shiba, T. 1991. Roseobacter litoralis gen. nov., sp. nov., and Roseobacter denitrificans sp. nov., aerobic pink-pigmented bacteria which contain bacteriochlorophyll a. Syst. Appl. Microbiol. 14:140-145.

17. Shiba, T. 1992. The genus Roseobacter, p. 2156-2159. In M. P. Starr, H. Stolp, H. G. Trüper, A. Balows, and H. G. Schlegel (ed.), The prokaryotes. Springer-Verlag, Berlin.

18. Smibert, R. M., and N. R. Krieg. 1981. General characterization, p. 409-443 In P. Gerhardt, R.G.E. Murray, R. N. Costilow, E. W. Nester, W. A. Wood, N. R. Krieg, and G. B. Phillips (ed.), Manual of methods for general bacteriology. American Society for Microbiology, Washington, D.C.

19. Smith, A. B., B. Lafay, and R. Christen. 1992. Comparative variation of morphological and molecular evolution through geologic time: $28 \mathrm{~S}$ ribosomal RNA versus morphology in echinoids. Philos. Trans. R. Soc. London B Bio. Sci. 338:365-382.

20. Sneath, P.H.A. 1993. Evidence from Aeromonas for genetic crossing-over in ribosomal sequences. Int. J. Syst. Bacteriol. 43:626-629.

21. Sritharan, V., and R.H.J. Barker. 1991. A simple method for diagnosing $M$. tuberculosis infection in clinical samples using PCR. Mol. Cell. Probes 5:385395.

22. Swofford, D. 1992. PAUP: phylogenetic analysis using parsimony, version 3.0s. Illinois Natural History Survey, Champaign.

23. ZoBell, C. E. 1941. Studies on marine bacteria. I. The cultural requirements of heterotrophic aerobes. J. Mar. Res. 4:42-75. 